\title{
Levothyroxine in Children
}

\author{
Gabriela Brenta
}

Thyroid hormones are essential for the development of the central nervous system early in life. Congenital hypothyroidism once caused the devastating cognitive and physical deficits of cretinism, but this condition is now detected routinely at birth using population-wide neonatal screening in most countries. Early and continuous treatment of these children with levothyroxine (LT4), according to age-specific reference ranges, ensures near-normal neuropsychological development, with preserved IQ, although the possibility of subtle residual effects on some indices of neuropsychological functioning remain an active area of research. Children who develop overt hypothyroidism also require treatment with LT4. Most children diagnosed with subclinical hypothyroidism are unlikely to require intervention with LT4, as this condition reverses spontaneously over time. These children should be monitored for possible deterioration of thyroid function in future, especially where thyroid autoimmunity is present.

\section{Introduction}

This chapter considers the aetiology, clinical course, and management of hypothyroidism in children. Thyroid hormones are essential for normal physical and neural development in neonates, and many countries include a measurement of thyrotropin (thyroid-stimulating hormone; TSH) in their neonatal screening programmes.

The genetic control of thyroid hormone levels appears to function similarly in children and adults [1]. Levels of thyroid hormones differ markedly with age, however. The average level of thyrotropin is high, and highly variable, compared with usual adult measurements $[2,3]$. One study showed that the average thyrotropin (thyroidstimulating hormone, TSH) level was $6.4 \mathrm{mIU} / \mathrm{L}$ at birth, declining to 5.5, 6.6, 3.8,

\footnotetext{
G. Brenta $(\varangle)$

Dr. Cesar Milstein Hospital, Buenos Aires, Argentina 


\section{a TSH}

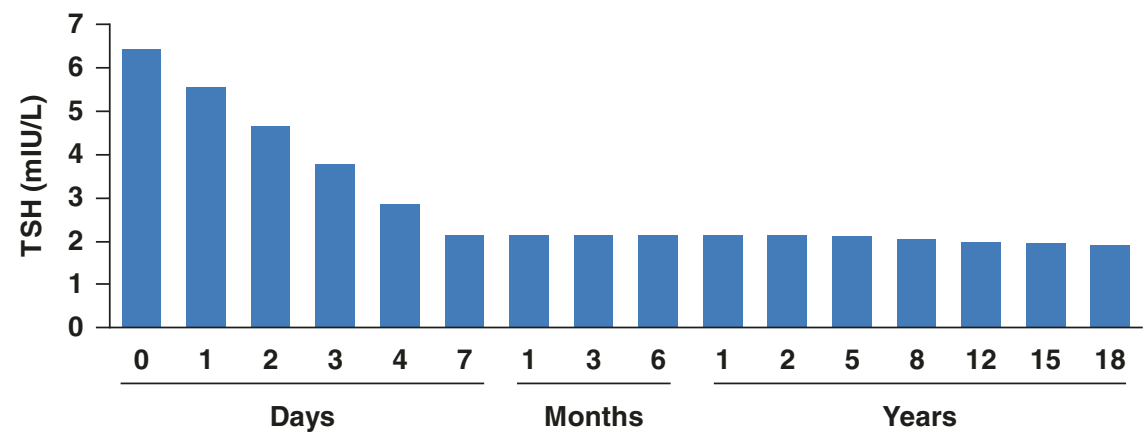

b Free T4

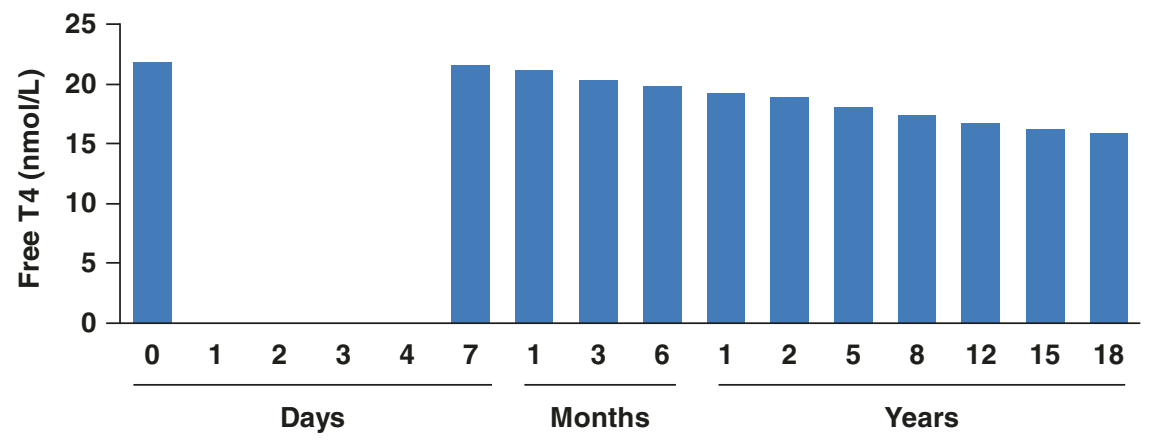

C Total T4

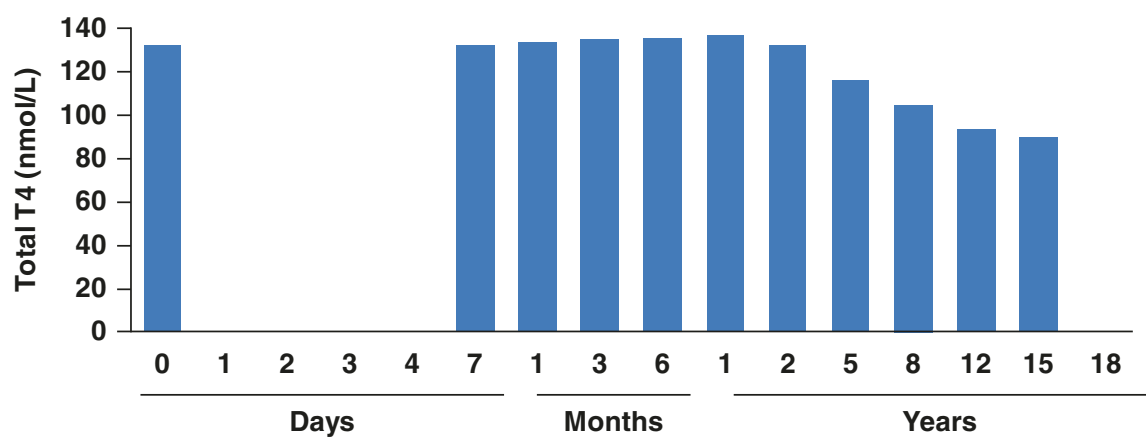

Fig. 1 Median values of (a) thyrotropin (TSH) and (b, c) free and total thyroxine (T4) calculated for children of different ages. Data were not presented between day of birth and 1 week of age for measurement of free or total T4, and for 18 years for measurement of total T4. (Drawn from data presented in Ref. [2])

2.9, and $2.1 \mathrm{mIU} / \mathrm{L}$ at 1, 2, 3, 4, and 7 days after birth, respectively [2]. Fig. 1 shows average levels of thyroid hormones from 1 month to 18 years of age [3].

Determination of reference ranges for thyroid hormones in other populations of children have confirmed the different evolution of levels of these hormones in children, compared with adults $[4,5]$. These data emphasise the importance of using ageappropriate reference ranges for the diagnosis of thyroid dysfunction [5]. In general, a TSH level > $5 \mathrm{mIU} / \mathrm{L}$ may be considered abnormal in children older than 1 month. 


\section{Overview of Hypothyroidism in Children}

\subsection{Congenital Hypothyroidism}

The recognition of the causative role of severe, untreated hypothyroidism in the disastrous neurodevelopmental damage associated with cretinism was an important milestone in the historical development of the field of thyroidology (see chapter, "Therapeutic Use of Levothyroxine: A Historical Perspective" of this book). However, hypothyroidism may be transient in newborns identified via neonatal screening, especially when the initial TSH level is mildly elevated at diagnosis, or when relatively low LT4 doses are required for the first 2 years of life [6]. Children with congenital hypothyroidism appear to be at increased genetic risk of other adverse outcomes, including other congenital defects [7], non-alcoholic fatty liver disease [8], or urinary tract disorders [9], compared with the general population.

The optimal TSH cut-off level to diagnose congenital hypothyroidism is still a matter of debate. A study from the USA showed that TSH levels only slightly outside the reference range (e.g. $\sim 5 \mathrm{mIU} / \mathrm{L}$ ) were a poor predictor of future thyroid dysfunction, and such children need not be referred for specialist care and possible treatment [10]. However, another research group calculated that a TSH cut-off value of $6 \mathrm{mIU} / \mathrm{L}$ was optimal for identifying congenital hypothyroidism (transient or permanent) that may have required treatment [11].

\subsection{Subclinical Hypothyroidism}

\subsubsection{Prevalence and Clinical Course}

The prevalence of subclinical hypothyroidism in paediatric subjects is reported as being $<2 \%$, generally lower than the prevalence of this condition in adults $[12,13]$. A large database analysis, conducted using records of more than 1 million paediatric outpatients, found that $\mathrm{TSH}$ was $5.5-10 \mathrm{mIU} / \mathrm{L}$ in $2.9 \%$, and $>10 \mathrm{mIU} / \mathrm{L}$ in $0.4 \%$ [14]. A recent study of more than 3 million children in Italy using administrative health databases for the years 2001-2014 found an annual prevalence of subclinical hypothyroidism (based on receipt of a low dose of LT4) of 1 case per 5000 children [15]. The annual prevalence remained relatively stable over time and tended to increase at age $>10$ years.

Many children with subclinical hypothyroidism revert to normal thyroid function or, at least, do not deteriorate to overt hypothyroidism [14, 16]. The analysis of $>1$ million children revealed that $\mathrm{TSH}$ reverted to within the normal range in $76 \%$ of children with initial $5.5-10 \mathrm{mIU} / \mathrm{L}$, and in $40 \%$ of those with initial TSH $>10 \mathrm{mIU} / \mathrm{L}$ [14]. The presence of thyroid autoimmunity, or higher levels of TSH at baseline, predicts a more severe clinical course, however [16-20]. In one study, the 
presence of Hashimoto's thyroiditis with high titres of anti-thyroglobulin antibodies was associated with a 28-fold higher risk of needing LT4 treatment vs. Hashimoto's thyroiditis patients without the presence of these antibodies [17]. Elsewhere, $63 \%$ of a population of girls with Hashimoto's thyroiditis and subclinical hypothyroidism required LT4 treatment during 5 years of follow-up, compared with 24\% of girls without autoimmunity; the proportions with overt hypothyroidism at 5 years were $31 \%$ (with thyroid autoimmunity) and $12 \%$ (without thyroid autoimmunity) [21]. Children with Hashimoto's thyroiditis may still recover normal thyroid function, as shown by a study which involved withdrawal of LT4 therapy from 148 children or adolescents with this condition. One third of the population did not need reinitiation of LT4 after 2 years off-treatment [22].

\subsubsection{Outcomes in Children with Subclinical Hypothyroidism}

Subclinical hypothyroidism is associated with obesity in paediatric subjects [23, 24]. A retrospective study identified subclinical hypothyroidism (normal FT4, TSH 5-10 mIU/L) in 36\% of a population of 215 obese children and adolescents [25]. Subjects with vs. without subclinical hypothyroidism were more insulin resistant and showed signs of atherogenic dyslipidaemia (low HDL-C, high triglycerides), but BMI was similar. Waist, BMI, LDL-C, serum triglycerides, and a measure of insulin resistance were higher, and HDL-C was lower, in 27 children (mean age 11 years) with subclinical hypothyroidism, compared with a control group [26]. Other studies have associated subclinical hypothyroidism with high blood pressure and/ or other components of the metabolic syndrome in children or adolescents [23, 24, 27-29]. The TSH level correlates with insulin resistance or triglycerides in euthyroid children, also [30].

A study in 32 children with autoimmune thyroiditis and subclinical hypothyroidism (mean age 14 years) revealed increased atherogenic index, a greater thickness of epicardial fat (an emerging risk factor for metabolic dysfunction), and reduced endothelial vascular function, compared with 32 healthy matched control children [31]. A further study in 64 children also associated subclinical hypothyroidism with dyslipidaemia and increased cIMT vs. controls, although upper diagnostic limit for TSH was $20 \mathrm{mIU} / \mathrm{L}$, and may have included children with overt hypothyroidism [32]. However, another observational study, in 110 obese children, found no correlation between TSH level and dyslipidaemia or carotid intima-media thickness, a measure of the overall burden of atherosclerosis [33].

Relatively mild neuropsychological deficits have been observed in children with subclinical hypothyroidism, relating mainly to indices of attention [12, 34, 35], or verbal memory/verbal recall [36]. Measures of intelligence of cognition were generally unaffected in these studies.

Finally, no impairment of growth or bone maturation was observed in a population of 36 children with persistent, untreated subclinical hypothyroidism followed for an average of 3.3 years [37]. 


\subsection{Other Causes of Hypothyroidism in Children}

Several other factors can produce a hypothyroid-like state in children, including consumptive hypothyroidism due to infantile hepatic hemangioma [38], older antiepileptic drugs [39], chronic liver disease [40], or gastrointestinal disorders [41]. Other autoimmune diseases, such as type 1 diabetes or celiac disease tend to cluster with hypothyroidism in children [42-44]. Hyperprolactinaemia is also strongly associated with thyroid status: a cross-sectional study of 602 children found this disorder on $32 \%$ of children with subclinical hypothyroidism and $52 \%$ of children with overt hypothyroidism [45]. Finally, the prevalence of hypothyroidism may be higher in children with Down syndrome or Turner Syndrome, compared with the general population [46-51].

Hypothyroidism can also follow partial thyroid resection. A retrospective review of 14 aged $<18$ years children who had undergone hemithyroidectomy for benign thyroid nodules showed that only one patient in six needed LT4 replacement [52]. The authors suggested that these patients should be followed for sufficient time to allow natural recovery of thyroid function, before administration of LT4.

\section{Effects of Levothyroxine in Children with Hypothyroidism}

\subsection{Congenital or Overt Hypothyroidism}

Children with any form of overt hypothyroidism must be treated promptly with LT4 [53]. Treatment for congenital hypothyroidism should start within the first 2 weeks of life, and even before a confirmatory thyroid function test in more severe cases $[54,55]$. A recommended starting dose is $10-15 \mathrm{mg} / \mathrm{kg} /$ day given orally, with the precise dose depending on the severity of the condition. Early and continuous treatment with LT4 effectively prevents the onset of the gross adverse effects of hypothyroidism in the brain [54]. For example, Fig. 2 shows the similar scores for measures of intelligence quotient (IQ) for children with early- and continuously treated congenital hypothyroidism, compared with euthyroid children in one study [56], and according to initial doses of LT4 in another study [57]. No behavioural abnormalities were observed between groups in the first study [56]. Optimisation of LT4 treatment is important in preserving neuropsychological outcomes in this population, as over- or under-treatment with LT4 early in life has been associated with neuropsychological or behavioural problems later on [56, 58, 59].

Severe hypothyroidism may be associated with subtle and long-lasting neurocognitive deficits, even when children are identified via new born screening and treated promptly with LT4. This was shown in a recent study in 30 such children aged at least 6 years, who demonstrated multiple brain white matter lesions, which correlated with deficits in language development [60]. A study from Turkey showed 
a

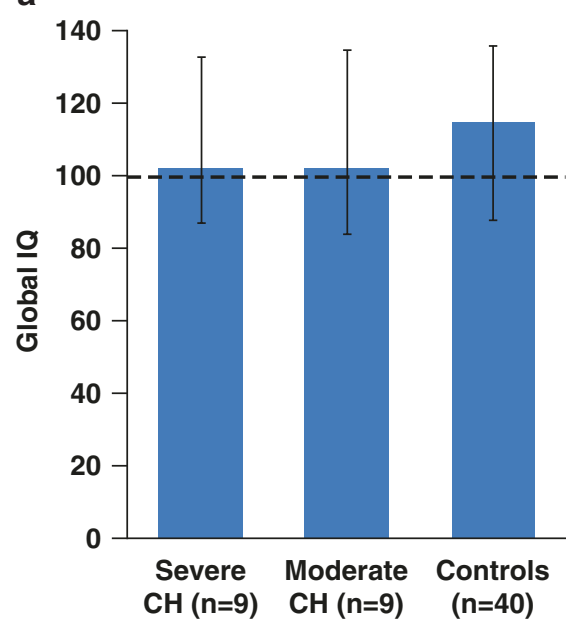

b

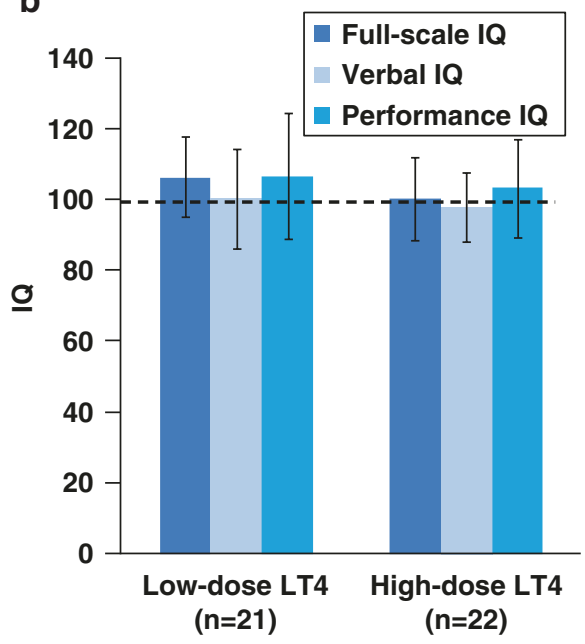

Fig. 2 Neuropsychological outcomes in children with congenital hypothyroidism $(\mathrm{CH})$ treated early and continuously with levothyroxine (LT4). (a) Study 1: global intelligence quotient measured at 5.75 years of age in children with $\mathrm{CH}$ of varying severity, and in euthyroid control children. Children with $\mathrm{CH}$ received LT4 at a median dose of $12 \mu \mathrm{g} / \mathrm{kg}$ from a median age of 14 days. Bars show range of measurements. Differences between groups were described as being not statistically significant (the source did not provide $p$ values). (Drawn from data presented in Ref. [56]). (b) Study 2: IQ measurements at 5.9 years of age in children with $\mathrm{CH}$ according to whether they had received a low or high dose of LT4. LT4 treatment started between 13 and 60 days after birth (mean 27 days). Low-dose LT4 $=6-<10 \mu \mathrm{g} / \mathrm{kg} / \mathrm{day}$; high-dose LT4 = 10-16 $\mu \mathrm{g} / \mathrm{kg} / \mathrm{day}$ ). Bars are $\mathrm{SD}$. There were no significant differences between low- and high-dose groups for any measure of IQ $(p=0.16-0.78)$. (Drawn from data presented in Ref. [57])

mild-to-moderate developmental delay at age 2-3 years in early-diagnosed and treated children with congenital hypothyroidism [61]. Ten-year old children with congenital hypothyroidism who were diagnosed via neonatal screening have been shown to be at risk of reduced health-related quality of life (HRQoL), and adverse perception of self-worth, compared with their euthyroid peers [62]. These deficits in QoL were independent of cognitive or neuropsychological functioning.

\subsection{Subclinical Hypothyroidism}

Individual studies have demonstrated that LT4 treatment reduced hypothyroidlike symptoms in children with subclinical hypothyroidism [63], or the mean antithyroglobulin titre in children with Hashimoto's thyroiditis [64]. Treatment of 
children with mild, subclinical hypothyroidism with LT4 was not disease modifying, in that it did not decrease the likelihood of an increase in TSH after treatment withdrawal [65]. There is little evidence to support improved neuropsychological outcomes with LT4 treatment in this population, however [34]. One prospective study found significantly reduced scores for verbal memory and verbal recall in 20 children with TSH 5-10 $\mu \mathrm{IU} / \mathrm{L}$, compared with a control group [36]. Treatment for 6 months with LT4 restored the test performance in the children with subclinical hypothyroidism to the level of controls.

Obesity is associated with hypothyroidism (especially the subclinical form) in children, as described above. A 6-month, randomised trial in 51 obese children with TSH 4-10 mIU/L (with or without abnormalities of other thyroid hormones) showed that administration of LT4 vs. no additional treatment, alongside weight loss interventions, had no significant effect on BMI or lipid abnormalities [66]. A similar study, where LT4 was or was not added to a behavioural intervention for obesity, reported similar results [67]. These data suggest there is no place for LT4 in the general management of obesity in children with TSH levels consistent with subclinical hypothyroidism. Correlations of higher TSH levels with higher BMI in hypothyroid children controlled on LT4 have been observed [68], but this association is probably not independently causative for obesity [1,69].

Administration of LT4 to 30 children with subclinical hypothyroidism (mean age 7 years, mean TSH $8.7 \mathrm{mIU} / \mathrm{L}$ ) for 6 months increased measures of left ventricular systolic performance (myocardial performance index, fraction shortening, and ejection fraction), but did not affect diastolic function (E/E' ratio) [70]. This study was uncontrolled, and these parameters were not overtly decreased before treatment, so that the clinical relevance of these findings is difficult to assess. Migraine may be a symptom of subclinical hypothyroidism, which responds to treatment with LT4 [71].

Box 1 summarises guideline recommendations for the management of subclinical hypothyroidism in children [43, 53, 69]. The majority of this population will not need active treatment, as long as thyroid hormones are within range and thyroid function is not deteriorating. The European guidance differs from the guidelines from Latin America and from the USA since it was specifically addressed for hypothyroidism in children, and it identifies the first 3 years of life as the crucial period for optimising thyroid function with LT4 (this is the time when thyroid hormones have their greatest influence on development of the brain). Monotherapy with LT4 is used exclusively: there is no role for the therapeutic use of T3 currently, as in other populations. A recent expert opinion recommends reserving LT4-based management of subclinical hypothyroidism to children with autoimmune (Hashimoto) disease, children whose thyroid function is deteriorating over time, or for children with goitre, other congenital abnormalities associated with thyroid dysfunction (Turner Syndrome or Down Syndrome) [72]. 


\section{Box 1: Summary of Guidance Relating to the Use of Levothyroxine}

(LT4) in Children with Subclinical Hypothyroidism [46, 53, 69]

- Discuss decisions to treat or not to treat with LT4 carefully with parents/ guardians

- Most children with TSH $<10 \mathrm{mIU} / \mathrm{L}$ and FT4 or TT4 within normal range will not need treatment with LT4

- Initiating LT4 is a reasonable strategy for patients with TSH $>10 \mathrm{mIU} / \mathrm{L}$, including children

- Especially beyond 1 month of age and who have signs and symptoms of hypothyroidism and/or risk factors for progression of thyroid dysfunction

- Use LT4 only, there is no current role for treatment with LT3

- Consider a trial of withdrawal of LT4 at age 3 years, as development of the CNS is no longer dependent on thyroid function

- Monitor the TSH level and for thyroid autoimmunity periodically beyond age 3 years (more frequent monitoring is recommended if thyroid autoimmunity is present already)

Guidance has been adapted and combined from Latin American [46], the USA [53], and European [69] guidelines and has been paraphrased for brevity. See the full guidelines for more details

\subsection{Biochemically Euthyroid Children}

A randomised trial in 59 biochemically euthyroid children with Hashimoto's thyroiditis showed that treatment with LT4 (mean dose $1.6 \mu \mathrm{g} / \mathrm{kg} / \mathrm{day}$, based individually on body weight) vs. no treatment reduced thyroid volume transiently, and did not affect either thyroid function or the level of thyroid autoantibodies [73]. Observational data from 330 children with autoimmune thyroiditis and type 1 diabetes showed a reduction in antibodies in the treated cohort, suggesting a possible role for LT4 therapy in this population [74].

\section{Conclusions}

Thyroid hormones are essential for the development of the central nervous system early in life. Early and continuous treatment with LT4 of children with overt hypothyroidism preserves near-normal neuropsychological development. Subclinical 
hypothyroidism often resolves spontaneously and most children will not need LT4 treatment. However, close observation is key since some children with this condition may require LT4 to manage symptoms, or they may develop overt hypothyroidism in the future.

\section{References}

1. Nielsen TR, Appel EV, Svendstrup M, et al. A genome-wide association study of thyroid stimulating hormone and free thyroxine in Danish children and adolescents. PLoS One. 2017; 12:e0174204.

2. Lem AJ, de Rijke YB, van Toor H, de Ridder MA, Visser TJ, Hokken-Koelega AC. Serum thyroid hormone levels in healthy children from birth to adulthood and in short children born small for gestational age. J Clin Endocrinol Metab. 2012;97:3170-8.

3. Kapelari K, Kirchlechner C, Högler W, Schweitzer K, Virgolini I, Moncayo R. Pediatric reference intervals for thyroid hormone levels from birth to adulthood: a retrospective study. BMC Endocr Disord. 2008;8:15.

4. Soldin OP, Jang M, Guo T, Soldin SJ. Pediatric reference intervals for free thyroxine and free triiodothyronine. Thyroid. 2009;19:699-702.

5. La'ulu SL, Rasmussen KJ, Straseski JA. Pediatric reference intervals for free thyroxine and free triiodothyronine by equilibrium dialysis-liquid chromatography-tandem mass spectrometry. J Clin Res Pediatr Endocrinol. 2016;8:26-31.

6. Kang MJ, Chung HR, Oh YJ, Shim YS, Yang S, Hwang IT. Three-year follow-up of children with abnormal newborn screening results for congenital hypothyroidism. Pediatr Neonatol. 2017;58:442-8.

7. Wędrychowicz A, Furtak A, Prośniak A, et al. Extrathyroidal congenital defects in children with congenital hypothyroidism-observations from a single paediatric centre in Central Europe with a review of literature. Pediatr Endocrinol Diabetes Metab. 2019;25:114-21.

8. Pan YW, Tsai MC, Yang YJ, Chen MY, Chen SY, Chou YY. The relationship between nonalcoholic fatty liver disease and pediatric congenital hypothyroidism patients. Kaohsiung J Med Sci. 2019;35:778-86.

9. Kumar J, Gordillo R, Kaskel FJ, Druschel CM, Woroniecki RP. Increased prevalence of renal and urinary tract anomalies in children with congenital hypothyroidism. J Pediatr. 2009;154:263-6.

10. Gammons S, Presley BK, White PC. Referrals for elevated thyroid stimulating hormone to pediatric endocrinologists. J Endocr Soc. 2019;3:2032-40.

11. Langham S, Hindmarsh P, Krywawych S, Peters C. Screening for congenital hypothyroidism: comparison of borderline screening cut-off points and the effect on the number of children treated with levothyroxine. Eur Thyroid J. 2013;2:180-6.

12. Wu T, Flowers JW, Tudiver F, Wilson JL, Punyasavatsut N. Subclinical thyroid disorders and cognitive performance among adolescents in the United States. BMC Pediatr. 2006;6:12.

13. Gallizzi R, Crisafulli C, Aversa T, et al. Subclinical hypothyroidism in children: is it always subclinical? Ital J Pediatr. 2018;44:25.

14. Lazar L, Frumkin RB, Battat E, Lebenthal Y, Phillip M, Meyerovitch J. Natural history of thyroid function tests over 5 years in a large pediatric cohort. J Clin Endocrinol Metab. 2009;94:1678-82.

15. Greggio NA, Rossi E, Calabria S, et al. Subclinical hypothyroidism in paediatric population treated with levothyroxine: a real-world study on 2001-2014 Italian administrative data. Endocr Connect. 2017;6:367-74. 
16. Valenzise M, Aversa T, Zirilli G, et al. Analysis of the factors affecting the evolution over time of subclinical hypothyroidism in children. Ital J Pediatr. 2017;43:2.

17. Lee YJ, Jung SY, Jung HW, et al. Unfavorable course of subclinical hypothyroidism in children with Hashimoto's thyroiditis compared to those with isolated non-autoimmune hyperthyrotropinemia. J Korean Med Sci. 2017;32:124-9.

18. Radetti G, Maselli M, Buzi F, et al. The natural history of the normal/mild elevated TSH serum levels in children and adolescents with Hashimoto's thyroiditis and isolated hyperthyrotropinaemia: a 3-year follow-up. Clin Endocrinol (Oxf). 2012;76:394-8.

19. Aversa T, Valenzise M, Corrias A, et al. Underlying Hashimoto's thyroiditis negatively affects the evolution of subclinical hypothyroidism in children irrespective of other concomitant risk factors. Thyroid. 2015;25:183-7.

20. Aversa T, Corrias A, Salerno M, et al. Five-year prospective evaluation of thyroid function test evolution in children with hashimoto's thyroiditis presenting with either euthyroidism or subclinical hypothyroidism. Thyroid. 2016;26:1450-6.

21. Wasniewska M, Aversa T, Salerno M, et al. Five-year prospective evaluation of thyroid function in girls with subclinical mild hypothyroidism of different etiology. Eur J Endocrinol. 2015;173:801-8.

22. Radetti G, Salerno M, Guzzetti C, et al. Thyroid function in children and adolescents with Hashimoto's thyroiditis after 1-thyroxine discontinuation. Endocr Connect. 2017;6:206-12.

23. Cerbone M, Capalbo D, Wasniewska M, et al. Cardiovascular risk factors in children with long-standing untreated idiopathic subclinical hypothyroidism. J Clin Endocrinol Metab. 2014;99:2697-703.

24. Zhang J, Jiang R, Li L, Li P, Li X, Wang Z, et al. Serum thyrotropin is positively correlated with the metabolic syndrome components of obesity and dyslipidemia in Chinese adolescents. Int J Endocrinol. 2014;2014:289503.

25. Kara O. Influence of subclinical hypothyroidism on metabolic parameters in obese children and adolescents. Clin Exp Pediatr. 2020;63:110-4.

26. Yadav Y, Saikia UK, Sarma D, Hazarika M. Cardiovascular risk factors in children and adolescents with subclinical hypothyroidism. Indian J Endocrinol Metab. 2017;21:823-9.

27. Chen H, Xi Q, Zhang H, et al. Investigation of thyroid function and blood pressure in schoolaged subjects without overt thyroid disease. Endocrine. 2012;41:122-9.

28. Ittermann T, Thamm M, Wallaschofski H, Rettig R, Völzke H. Serum thyroid stimulating hormone levels are associated with blood pressure in children and adolescents. Clin Endocrinol Metab. 2012;97:828-84.

29. Cerbone M, Capalbo D, Wasniewska M, et al. Effects of L-thyroxine treatment on early markers of atherosclerotic disease in children with subclinical hypothyroidism. Eur J Endocrinol. 2016;175:11-9.

30. Nader NS, Bahn RS, Johnson MD, Weaver AL, Singh R, Kumar S. Relationships between thyroid function and lipid status or insulin resistance in a pediatric population. Thyroid. 2010;20:1333-9.

31. Farghaly HS, Metwalley KA, Raafat DM, Algowhary M, Said GM. Epicardial fat thickness in children with subclinical hypothyroidism and its relationship to subclinical atherosclerosis: a pilot study. Horm Res Paediatr. 2019;92:99-105.

32. Unal E, Akın A, Yıldırım R, Demir V, Yildiz İ, Haspolat YK. Association of subclinical hypothyroidism with dyslipidemia and increased carotid intima-media thickness in children. J Clin Res Pediatr Endocrinol. 2017;9:144-9.

33. Rumińska M, Witkowska-Sędek E, Majcher A, Brzewski M, Krawczyk M, Pyrżak B. Serum TSH level in obese children and its correlations with atherogenic lipid indicators and carotid intima media thickness. J Ultrason. 2018;18:296-301.

34. Aijaz NJ, Flaherty EM, Preston T, Bracken SS, Lane AH, Wilson TA. Neurocognitive function in children with compensated hypothyroidism: lack of short term effects on or off thyroxin. BMC Endocr Disord. 2006;6:2. 
35. Ergür AT, Taner Y, Ata E, Melek E, Bakar EE, Sancak T. Neurocognitive functions in children and adolescents with subclinical hypothyroidism. J Clin Res Pediatr Endocrinol. 2012;4:21-4.

36. Sangün Ö, Demirci S, Dündar N, et al. The effects of six-month L-Thyroxine treatment on cognitive functions and event-related brain potentials in children with subclinical hypothyroidism. J Clin Res Pediatr Endocrinol. 2015;7:102-8.

37. Cerbone M, Bravaccio C, Capalbo D, et al. Linear growth and intellectual outcome in children with long-term idiopathic subclinical hypothyroidism. Eur J Endocrinol. 2011;164:591-7.

38. Weber Pasa M, Selbach Scheffel R, Borsatto Zanella A, Maia AL, Dora JM. Consumptive hypothyroidism: case report of hepatic hemangioendotheliomas successfully treated with vincristine and systematic review of the syndrome. Eur Thyroid J. 2017;6:321-7.

39. Elshorbagy HH, Barseem NF, Suliman HA, et al. The impact of antiepileptic drugs on thyroid function in children with epilepsy: new versus old. Iran J Child Neurol. 2020;14:31-41.

40. Ön ŞŞ, Acar S, Demir K, et al. Evaluation of thyroid function tests in children with chronic liver diseases. J Clin Res Pediatr Endocrinol. 2020;12:143-9.

41. Passos ACV, Barros F, Damiani D, et al. Hypothyroidism associated with short bowel syndrome in children: a report of six cases. Arch Endocrinol Metab. 2018;62:655-60.

42. Ridha MF, Al Zubaidi MA. Thyroid auto immune antibodies in children with type-I diabetes mellitus in relation to diabetes control. Pak J Med Sci. 2019;35:969-73.

43. Sharma B, Nehara HR, Saran S, Bhavi VK, Singh AK, Mathur SK. Coexistence of autoimmune disorders and type 1 diabetes mellitus in children: an observation from western part of India. Indian J Endocrinol Metab. 2019;23:22-6.

44. Kakleas K, Paschali E, Kefalas N, et al. Factors for thyroid autoimmunity in children and adolescents with type 1 diabetes mellitus. Ups J Med Sci. 2009;114:214-20.

45. Sharma N, Dutta D, Sharma LK. Hyperprolactinemia in children with subclinical hypothyroidism. J Clin Res Pediatr Endocrinol. 2017;9:350-4.

46. Brenta G, Vaisman M, Sgarbi JA, et al. Clinical practice guidelines for the management of hypothyroidism. Arq Bras Endocrinol Metabol. 2013;57:265-91.

47. Pierce MJ, LaFranchi SH, Pinter JD. Characterization of thyroid abnormalities in a large cohort of children with Down syndrome. Horm Res Paediatr. 2017;87:170-8.

48. Kowalczyk K, Pukajło K, Malczewska A, Król-Chwastek A, Barg E. L-thyroxine therapy and growth processes in children with Down syndrome. Adv Clin Exp Med. 2013;22:85-92.

49. De Sanctis V, Khater D. Autoimmune diseases in Turner syndrome: an overview. Acta Biomed. 2019;90:341-4.

50. Liu MY, Lee CT, Lee NC, et al. Thyroid disorders in Taiwanese children with Down syndrome: the experience of a single medical center. J Formos Med Assoc. 2020;119:345-9.

51. Yaqoob M, Manzoor J, Hyder SN, Sadiq M. Congenital heart disease and thyroid dysfunction in Down syndrome reported at Children's Hospital, Lahore, Pakistan. Turk J Pediatr. 2019;61:915-24.

52. Chen J, Hou S, Li X, Yang J. Management of subclinical and overt hypothyroidism following hemithyroidectomy in children and adolescents: a pilot study. Front Pediatr. 2019;7:396.

53. Jonklaas J, Bianco AC, Bauer AJ, et al. Guidelines for the treatment of hypothyroidism: prepared by the American Thyroid Association task force on thyroid hormone replacement. Thyroid. 2014;24:1670-751.

54. Léger J, Olivieri A, Donaldson M, et al. European Society for Paediatric Endocrinology consensus guidelines on screening, diagnosis, and management of congenital hypothyroidism. J Clin Endocrinol Metab. 2014;99:363-84.

55. Rastogi MV, LaFranchi SH. Congenital hypothyroidism. Orphanet J Rare Dis. 2010;5:17.

56. Simoneau-Roy J, Marti S, Deal C, Huot C, Robaey P, Van Vliet G. Cognition and behavior at school entry in children with congenital hypothyroidism treated early with high-dose levothyroxine. J Pediatr. 2004;144:747-52.

57. Seo MK, Yoon JS, So CH, Lee HS, Hwang JS. Intellectual development in preschool children with early treated congenital hypothyroidism. Ann Pediatr Endocrinol Metab. 2017;22:102-7. 
58. García Morales L, Rodríguez Arnao MD, Rodríguez Sánchez A, Dulín Íñiguez E, Álvarez González MA. Sustained attention in school-age children with congenital hypothyroidism: influence of episodes of overtreatment in the first three years of life. Neurologia. 2017. pii: S0213-4853(17)30299-2.

59. Bongers-Schokking JJ, Resing WCM, Oostdijk W, de Rijke YB, de Muinck Keizer-Schrama SMPF. Relation between early over- and undertreatment and behavioural problems in preadolescent children with congenital hypothyroidism. Horm Res Paediatr. 2018;90:247-56.

60. Cooper HE, Kaden E, Halliday LF, et al. White matter microstructural abnormalities in children with severe congenital hypothyroidism. Neuroimage Clin. 2019;24:101980.

61. Baysal BT, Baysal B, Genel F, et al. Neurodevelopmental outcome of children with congenital hypothyroidism diagnosed in a national screening program in Turkey. Indian Pediatr. 2017;54:381-4.

62. van der Sluijs VL, Kempers MJ, Maurice-Stam H, Last BF, Vulsma T, Grootenhuis MA. Healthrelated quality of life and self-worth in 10-year old children with congenital hypothyroidism diagnosed by neonatal screening. Child Adolesc Psychiatry Ment Health. 2012;6:32.

63. Çatı G, Anık A, Ünver Tuhan H, Böber E, Abacı A. The effect of L-thyroxine treatment on hypothyroid symptom scores and lipid profile in children with subclinical hypothyroidism. J Clin Res Pediatr Endocrinol. 2014;6:238-44.

64. Özen S, Berk Ö, Şimşek DG, Darcan S. Clinical course of Hashimoto's thyroiditis and effects of levothyroxine therapy on the clinical course of the disease in children and adolescents. J Clin Res Pediatr Endocrinol. 2011;3:192-7.

65. Wasniewska M, Corrias A, Aversa T, et al. Comparative evaluation of therapy with L-thyroxine versus no treatment in children with idiopathic and mild subclinical hypothyroidism. Horm Res Paediatr. 2012;77:376-81.

66. Kumar S, Dayal D, Attri S, Gupta A, Bhalla A. Levothyroxine supplementation for obesityassociated thyroid dysfunction in children: a prospective, randomized, case control study. Pediatr Endocrinol Diabetes Metab. 2019;25:107-13.

67. Matusik P, Gawlik A, Januszek-Trzciakowska A, Malecka-Tendera E. Isolated subclinical hyperthyrotropinemia in obese children: does levothyroxine (LT4) improve weight reduction during combined behavioral therapy? Int J Endocrinol. 2015;2015:792509.

68. Shaoba A, Basu S, Mantis S, Minutti C. Serum thyroid-stimulating hormone levels and body mass index percentiles in children with primary hypothyroidism on levothyroxine replacement. J Clin Res Pediatr Endocrinol. 2017;9:337-43.

69. Lazarus J, Brown RS, Daumerie C, Hubalewska-Dydejczyk A, Negro R, Vaidya B. 2014 European Thyroid Association guidelines for the management of subclinical hypothyroidism in pregnancy and in children. Eur Thyroid J. 2014;3:76-94.

70. Banu Rupani N, Alijanpour M, Babazadeh K, Hajian-Tilaki K, Moadabdoost F. Effect of levothyroxine on cardiac function in children with subclinical hypothyroidism: a quasiexperimental study. Caspian J Intern Med. 2019;10:332-8.

71. Mirouliaei M, Fallah R, Bashardoost N, Partovee M, Ordooei M. Efficacy of levothyroxine in migraine headaches in children with subclinical hypothyroidism. Iran J Child Neurol. 2012;6:23-6.

72. Crisafulli G, Aversa T, Zirilli G, et al. Subclinical hypothyroidism in children: when a replacement hormonal treatment might be advisable. Front Endocrinol (Lausanne). 2019;10:109.

73. Dörr HG, Bettendorf M, Binder G, et al. Levothyroxine treatment of euthyroid children with autoimmune Hashimoto thyroiditis: results of a multicenter, randomized, controlled trial. Horm Res Paediatr. 2015;84:266-74.

74. Korzeniowska K, Jarosz-Chobot P, Szypowska A, et al. L-thyroxine stabilizes autoimmune inflammatory process in euthyroid nongoitrous children with Hashimoto's thyroiditis and type 1 diabetes mellitus. J Clin Res Pediatr Endocrinol. 2013;5:240-4. 
Open Access This chapter is licensed under the terms of the Creative Commons Attribution 4.0 International License (http://creativecommons.org/licenses/by/4.0/), which permits use, sharing, adaptation, distribution and reproduction in any medium or format, as long as you give appropriate credit to the original author(s) and the source, provide a link to the Creative Commons license and indicate if changes were made.

The images or other third party material in this chapter are included in the chapter's Creative Commons license, unless indicated otherwise in a credit line to the material. If material is not included in the chapter's Creative Commons license and your intended use is not permitted by statutory regulation or exceeds the permitted use, you will need to obtain permission directly from the copyright holder.

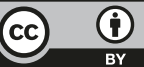

